\title{
Dosimetric Comparison of a-Si 1200 and a-Si 1000 Electronic Portal Imager for Intensity Modulated Radiation Therapy (IMRT)
}

\author{
Vaibhav Mhatre*, Shaju Pilakkal, Pranav Chadha and Kaustav Talpatra
}

Department of Radiation Oncology, Kokilaben Dhirubhai Ambani Hospital and Research Centre, Mumbai, India

\begin{abstract}
Aim: This study investigates the dosimetric impact of a-Si 1200 over a-Si 1000 portal imager for $6 \mathrm{MV}$ photon beam of a Varian Amorphous Silicon Electronic Portal Imaging Device (a-Si EPID) installed on Edge and Novalis TxLinac.

Materials and Methods: The performance of an a-SiEPID 1200 was assessed and compared to its performance with a-Si EPID 1000 and dose measurements using an ionization chamber. This study was conducted for 6MV photon energy and the EPID performance was assessed as function of the delivered dose, dose rate, field size, SDD effect, Ghosting effect, Backscatter arm shielding impact and intensity-modulated radiation therapy fields.

Results: The dose response for a-Si 1200 was within $0.5 \%$ for low MU (2-10) as compared to $1.4 \%$ for a-Si 1000 portal imager and less than $1 \%$ for both the imager above $10 \mathrm{MU}$. The output factor variation for $25 \times$ $25 \mathrm{~cm}^{2}$ was $1.3 \%$ for a-Si 1200 and $3.8 \%$ for a-Si 1000 when compared with ionisation chamber. The ghosting was measured to be $0.2 \%$ for a-Si 1200 as compared to $0.8 \%$ for a-Si 1000 portal imager. There is a significant improvement in a-Si 1200 portal image due to backscatter shielding material attached to the back of the panel of a-Si 1200 portal imager.
\end{abstract}

Conclusion: The new aS1200 detector showed a significant dosimetric improvement when compared with previous aS1000 hence providing more accurate measurements for pre-treatment patient specific Quality Assurance (QA).

Keywords: Electronic portal imager; Dosimetry; IMRT; Quality assurance

\section{Introduction}

In the recent years IMRT in clinical routine has been rapidly increasing due to its better target coverage with normal tissue sparing. The complexity of IMRT demands accurate quality assurance before the treatment delivery. Film dosimetry for pre-treatment verification of patient-specific IMRT dose distribution is the gold standard due to its high resolution [1-4]. But the dose response of film is affected by processing conditions hence films are gradually being replaced by twodimensional (2D) detector arrays due to their ease of use and instant results. Dosimetric characteristics and clinical implementation of $2 \mathrm{D}$ detector arrays consisting of a large number of ionization chambers or diodes have been reported for pre-treatment verification of IMRT plans [5-10]. A more efficient tool for pre-treatment QA is the EPID as it is mounted on linac, providing real time feedback to the user. Although the primary purpose of EPID is to verify patient positioning, but with the introduction of on board imagers for image guidance the EPID has been more utilised for machine QA and pre-treatment patient specific QA [11-14]. Dosimetry using EPIDs or portal dosimetry has received considerable attention recently due to its relatively high-resolution of $0.392 \mathrm{~mm}$ amorphous silicon (a-Si) flat-panel detector [15-18]. Several authors have extensively studied the dosimetric properties of a-Si 500 and a-Si 1000 EPID and its application in IMRT [19-25]. Varian has recently released a-Si 1200 portal imager with larger area, high resolution of $0.336 \mathrm{~mm}$ and improved backscatter for dosimetry. Varian has adapted a-Si 1200 portal imager for the use of FFF beams without saturation at any source to detector distance [26-27].

Recently we commissioned a-Si1200 EPID and Portal Dose Prediction (PDP) algorithm in Eclipse (Varian Medical Systems, Palo Alto, CA) Treatment Planning System (TPS) for portal dosimetry. This study aims to compare the dosimetric properties of new a-Si
1200 EPID with Varian Edge linac along with a-Si 1000 portal imager. The dosimetric factors include delivered dose, dose rate, Source to Detector Distance (SDD) effect, field size dependence, ghosting effect, impact of backscatter shielding over a-Si 1000 portal arm and common IMRT fields. The responses were compared with the measurements of calibrated $0.6 \mathrm{cc}$ volume ionisation chamber.

\section{Materials and Methods}

In this study all the measurements were performed on a-Si 1200 EPID with Varian Edge linear accelerator and a-Si 1000 portal imager attached with Novalis Tx accelerator. The high resolution a-Si1000 EPID, available for patient set-up verification used in this study has arrays of light sensitive amorphous-Si photodiodes arranged in $40 \times$ $30 \mathrm{~cm}^{2}$ active detector area with $1024 \times 768$ pixels, and pixel pitch of $0.390 \mathrm{~mm}$. The a-Si 1200 EPID detector was released recently and has an active area of $40 \times 40 \mathrm{~cm}^{2}$ with $1190 \times 1190$ pixel arrays and pixel pitch of $0.336 \mathrm{~mm}$. From outside, the imager looks the same [26]. The change is hidden behind the MV imager's cover as shown in Figure 1.

All the measurements were done for $6 \mathrm{MV}$ photon beam. The comparison of a-Si 1200 and a-Si 1000 are given in Table 1 .

*Corresponding author: Vaibhav Mhatre, Department of Radiation Oncology Kokilaben Dhirubhai Ambani Hospital and Research Centre, Mumbai, India, Tel: 09920428348; E-mail: vaibhav.mhatre@relianceada.com

Received January 23, 2018; Accepted February 08, 2018; Published February 20, 2018

Citation: Mhatre V, Pilakkal S, Chadha P, Talpatra K (2018) Dosimetric Comparison of a-Si 1200 and a-Si 1000 Electronic Portal Imager for Intensity Modulated Radiation Therapy (IMRT). J Nucl Med Radiat Ther 9: 354. doi: 10.4172/21559619.1000354

Copyright: ( 2018 Mhatre V, et al. This is an open-access article distributed under the terms of the Creative Commons Attribution License, which permits unrestricted use, distribution, and reproduction in any medium, provided the original author and source are credited. 


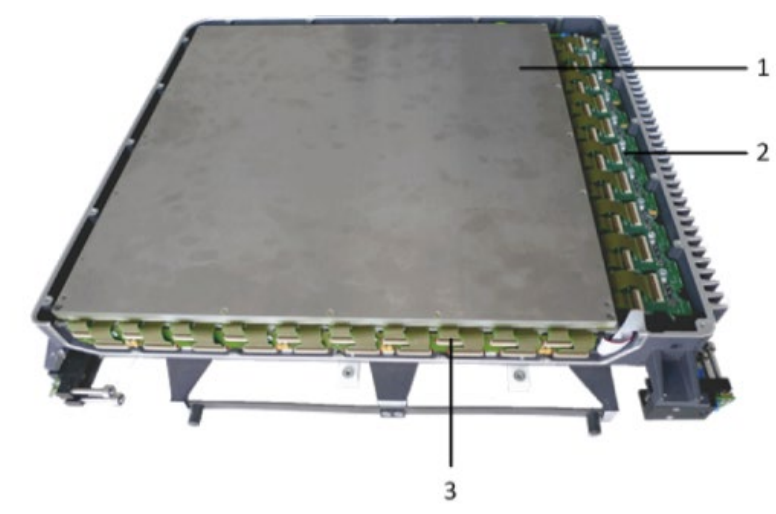

1. Photodiode array (sensitive area)

2. Readout electronics. Converts charge to analog signal.

3. Gate Driver. Pixel activation

Figure 1: MV detection Unit a-Si 1200.

\begin{tabular}{|l|c|c|}
\hline EPID Model & a-Si 1000 & a-Si 1200 \\
\hline Max irradiated area $\left(\mathrm{cm}^{2}\right)$ & $30 \times 40$ & $43 \times 43$ \\
\hline Active area $\left(\mathrm{cm}^{2}\right)$ & $30 \times 40$ & $40 \times 40$ \\
\hline Total pixel matrix & $768 \times 1024$ & $1280 \times 1280$ \\
\hline Active dosimetry matrix & $768 \times 1024$ & $1190 \times 1190$ \\
\hline Pixel size $(\mathrm{mm})$ & 0.39 & 0.34 \\
\hline
\end{tabular}

Table 1: Comparison of a-Si 1200 and a-Si 1000 portal imager.

\section{Dosimetric properties of electronic portal imaging device}

Linearity with delivered dose: To verify linearity of EPID dose response versus delivered dose detector was irradiated with a dose range of $2,3,4,5,8,10,15,20,25,30,40,50,60,75,100,200,300,500$ and 600 monitor units for a field size of $10 \mathrm{~cm} \times 10 \mathrm{~cm}^{2}$ for $6 \mathrm{MV}$ at fixed dose rate $600 \mathrm{MU} / \mathrm{min}$ with imager at $105 \mathrm{~cm}$. The mean pixel value of $10 \times 10$ matrix measured at the centre of the field was measured and graph was plotted against MU.

Dose rate linearity: The linearity of EPID to dose rate was also verified in order to rule out any variations on EPID signal due to dose rate. A dose of $100 \mathrm{MU}$ was delivered for $6 \mathrm{MV}$ beam with a dose rate of 100 to $600 \mathrm{MU} / \mathrm{min}$ for $10 \times 10 \mathrm{~cm}^{2}$ field size.

Field size dependence: Open square fields of size: $3 \mathrm{~cm}^{2}, 4 \mathrm{~cm}^{2}, 5$ $\mathrm{cm}^{2}, 8 \mathrm{~cm}^{2}, 10 \mathrm{~cm}^{2}, 12 \mathrm{~cm}^{2}, 15 \mathrm{~cm}^{2}, 20 \mathrm{~cm}^{2}$ and $25 \mathrm{~cm}^{2}$ were delivered with $50 \mathrm{MU}$ with $400 \mathrm{MU} / \mathrm{min}$ at $105 \mathrm{~cm}$. Results were normalized to that response for $10 \times 10 \mathrm{~cm}^{2}$ field size. The results were compared with those of ionisation chamber measurements.

Ghosting effect: Ghosting is artefact in the image produced due the signals being present in frames subsequent to the frame in which it was generated. It was measured in a similar manner to that employed by Van Esch et al. and Greer and Popescu [28-30]. To assess the existence of memory effect for portal imagers the detector was exposed for $500 \mathrm{MU}$ in $5 \times 5 \mathrm{~cm}^{2}$ static field immediately followed by delivery of $10 \mathrm{MU}$ in 15 $\times 15 \mathrm{~cm}^{2}$ static field. The interval between the two consecutive images was $15 \mathrm{sec}$. Then after a gap of $15 \mathrm{~min}$ another $10 \mathrm{MU}$ was delivered for $15 \times 15 \mathrm{~cm}^{2}$ field and was kept as a reference for comparison of profile across $15 \times 15 \mathrm{~cm}^{2}$ field.

Effect of SDD: To evaluate the impact of SDD on EPID the detectors were irradiated with SDD of $105 \mathrm{~cm}, 105.5 \mathrm{~cm}, 106 \mathrm{~cm}, 106.5 \mathrm{~cm}, 107$ $\mathrm{cm}, 107.5 \mathrm{~cm}, 108 \mathrm{~cm}, 109 \mathrm{~cm}, 110 \mathrm{~cm}$ with $100 \mathrm{MU}$ and a field size of $10 \times 10 \mathrm{~cm}^{2}$.

Backscatter impact: To verify the effectiveness of a-Si 1200 backscatter shielding layers, cross plane and in plane profiles were compared through the central axis for different field sizes ranging from $2 \times 2$ to $27 \times 27 \mathrm{~cm}^{2}$.

Intensity modulated radiation therapy delivery: A clinical dynamic IMRT plans were delivered using $6 \mathrm{MV}$ and a dose rate of 400 $\mathrm{MU} / \mathrm{min}$ on both the portals and the gamma evaluations of measured dose against TPS doses were performed for 20 IMRT cases. All the cases were planned in Eclipse Planning system and with same planning constraints for both the linac.

\section{Results}

\section{Linearity with delivered dose}

Both the detectors showed excellent linearity with monitor units ranging from $2 \mathrm{MU}$ to $600 \mathrm{MU}$ when compared with ion chamber as shown in Figure 2. The dose response for a-Si 1200 was within $0.5 \%$ for low MU (2-10) as compared to $1.4 \%$ for a-Si 1000 portal imager and less than $1 \%$ for both the imager above $10 \mathrm{MU}$.

\section{Linearity with dose rate}

The detector panel did not exhibit any dose rate saturation in response to the dose rate range 100 to $600 \mathrm{MU} / \mathrm{min}$ as shown in Figure 3. The a-Si 1200 imager showed a better agreement with ionisation chamber as compared to a-Si 1000 portal imager.

\section{Field size dependence}

The field size output factors of both the EPID's and farmer type chamber are shown in Figure 4. Variations are larger for field size $>20$

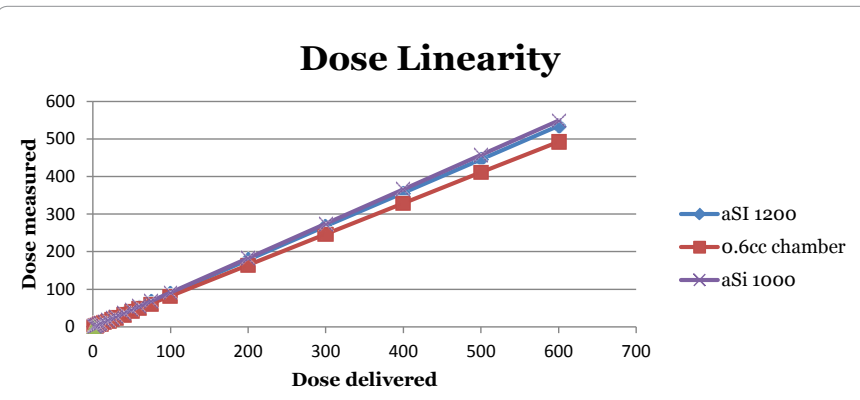

Figure 2: Dose linearity response of a-Si 1200 and a-Si 1000 with ionization chamber.

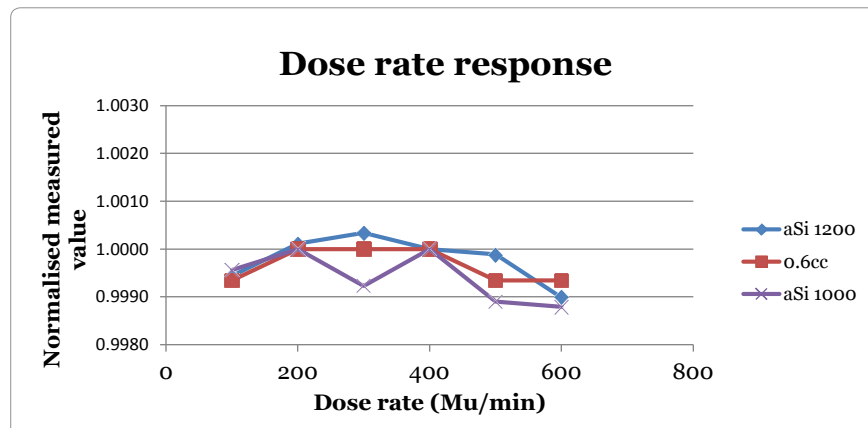

Figure 3: Dose rate response of a-Si 1200 and a-Si 1000 with ionization chamber. 


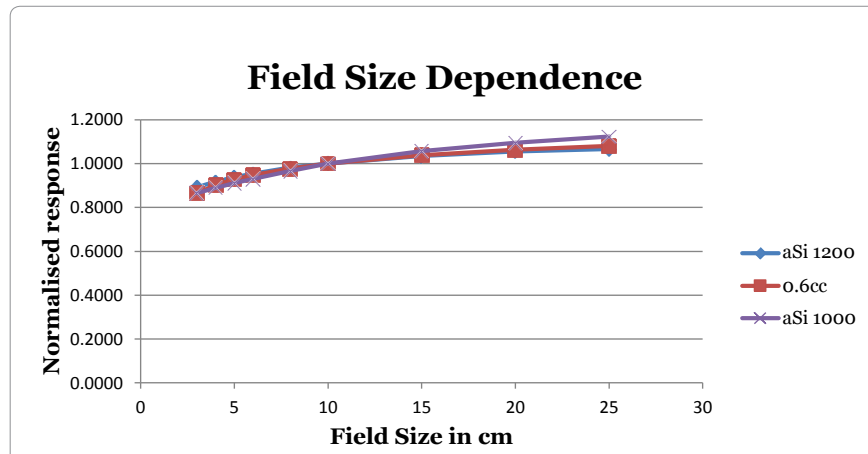

Figure 4: Field size output factors a-Si 1200 and a-Si 1000 with ionization chamber.

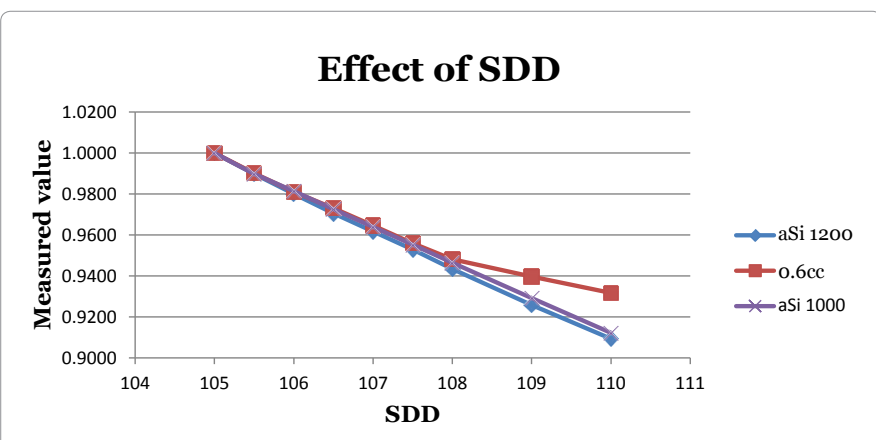

Figure 5: Effect of SDD for a-Si 1200 and a-Si 1000 with ionization chamber.

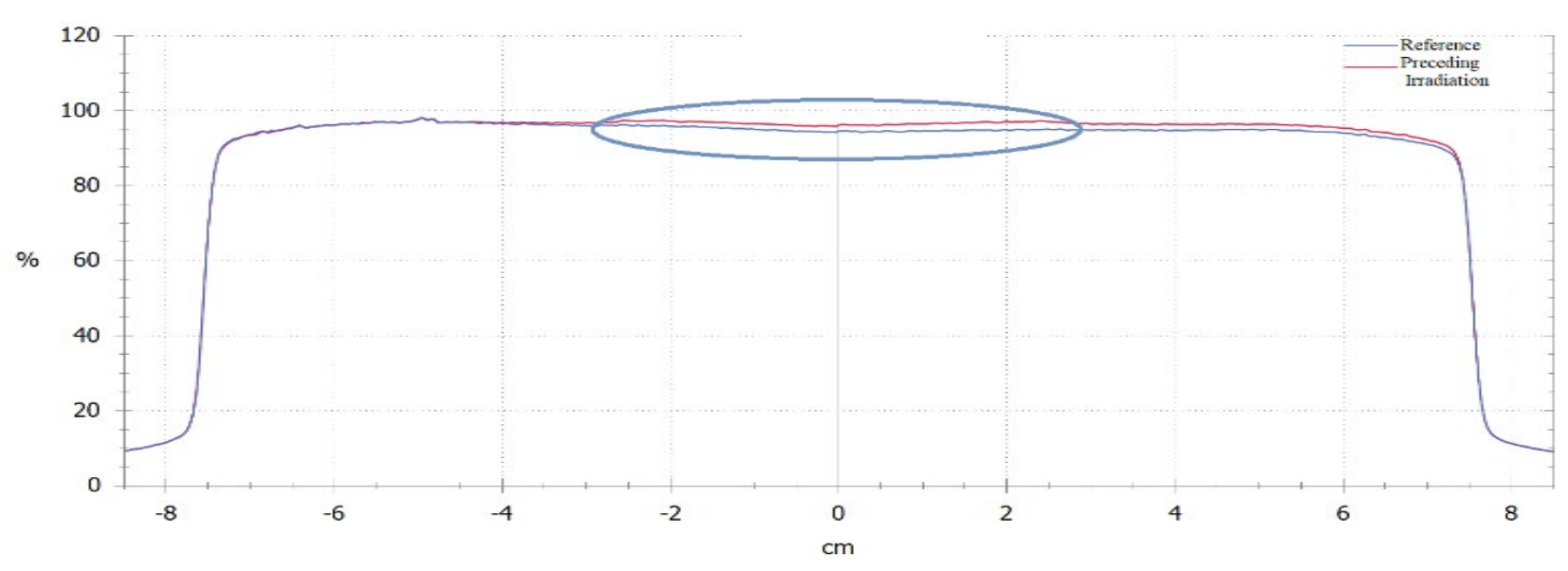

Figure 6a: Line profiles of $15 \times 15 \mathrm{~cm}$ static field for a-Si 1000 portal indicating the ghosting effect.

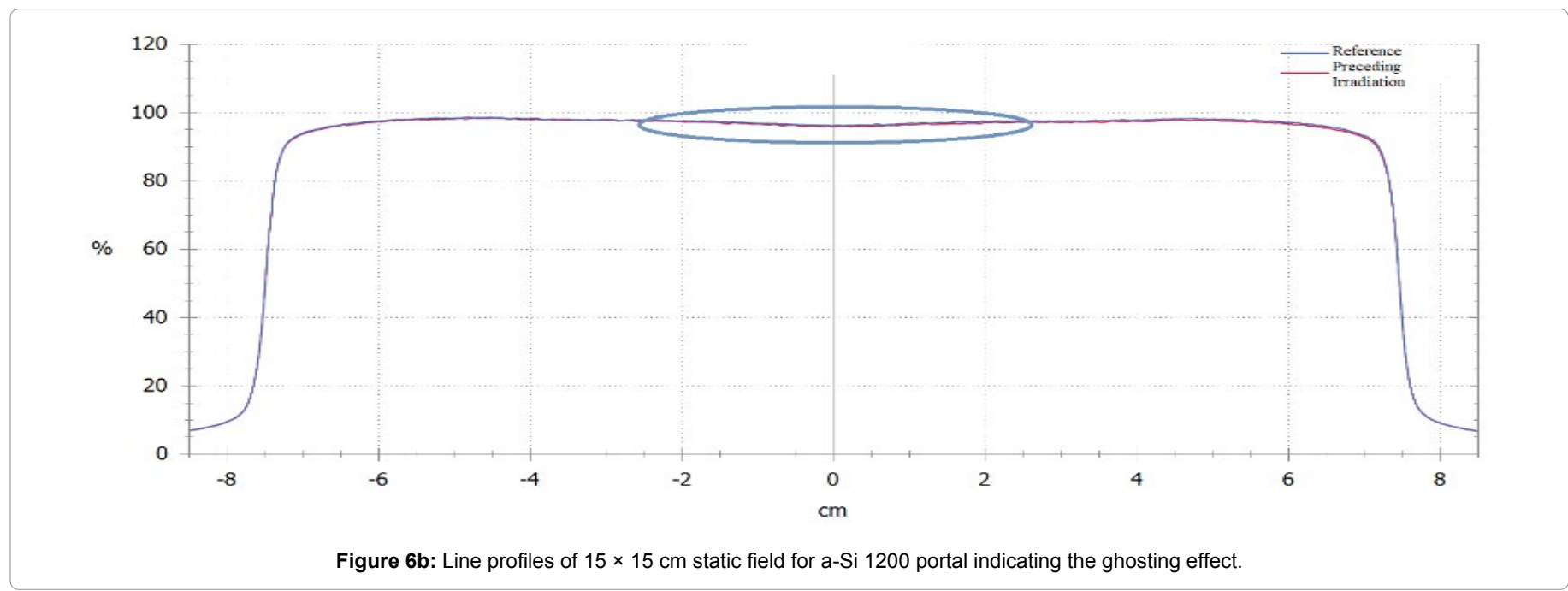

$\times 20 \mathrm{~cm}$ for a-Si 1000 as compared with a-Si 1200. The variation for 25 $\times 25 \mathrm{~cm}$ was $1.3 \%$ for a-Si 1200 and $3.8 \%$ for a-Si 1000 when compared with ionisation chamber.

\section{Effect of SDD}

Both the detectors showed similar response when compared with ion chamber on SDD variation as shown in Figure 5.

\section{Ghosting effect}

The residual of foregoing irradiation of $5 \times 5 \mathrm{~cm}$ field exposed with $500 \mathrm{MU}$ in the image of larger field $15 \times 15$ acquired immediately with $10 \mathrm{MU}$ for both the imagers are shown in Figures $6 \mathrm{a}$ and $6 \mathrm{~b}$. The 


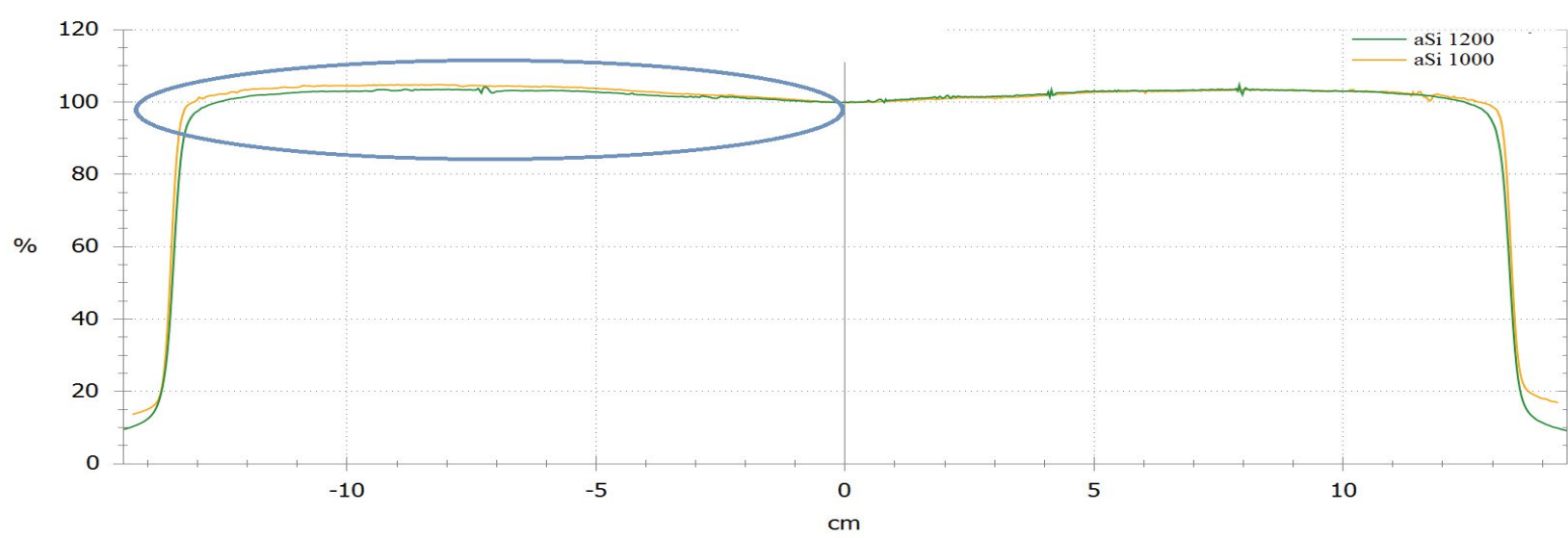

Figure 7: In plane profile to examine impact of backscatter shielding on a-Si 1200 and a-Si 1000 portal imager.

\begin{tabular}{|c|c|c|c|c|c|c|}
\hline \multirow{2}{*}{ Cases } & \multicolumn{3}{|c|}{ a-Si 1200 Portal dosimetry -Gamma values with $3 \% 3 \mathrm{~mm}$ criteria } & \multicolumn{3}{|c|}{ a-Si 1000 Portal dosimetry -Gamma values with $3 \% 3 \mathrm{~mm}$ criteria } \\
\hline & Area Gamma $<1$ & Max Gamma & Avg Gamma & Area Gamma $<1$ & Max Gamma & Avg Gamma \\
\hline 1 & 99.5 & 2.13 & 0.26 & 95.1 & 2.33 & 0.4 \\
\hline 2 & 98.8 & 2.27 & 0.3 & 95.8 & 2.8 & 0.4 \\
\hline 3 & 98.6 & 2 & 0.25 & 95.3 & 3 & 0.35 \\
\hline 4 & 99.3 & 1.9 & 0.24 & 96.3 & 2.7 & 0.35 \\
\hline 5 & 99.7 & 1.3 & 0.26 & 97 & 2 & 0.35 \\
\hline 6 & 98.5 & 1.9 & 0.37 & 98 & 2.5 & 0.5 \\
\hline 7 & 99.8 & 2 & 0.32 & 98.5 & 3.1 & 0.45 \\
\hline 8 & 98 & 2.2 & 0.24 & 98 & 2.5 & 0.38 \\
\hline 9 & 99.4 & 2.1 & 0.32 & 98 & 2.7 & 0.5 \\
\hline 10 & 99.9 & 1.5 & 0.33 & 97 & 1.7 & 0.46 \\
\hline 11 & 97.7 & 1.4 & 0.26 & 95.5 & 1.8 & 0.38 \\
\hline 12 & 98.1 & 1.89 & 0.22 & 97 & 1.9 & 0.3 \\
\hline 13 & 99.8 & 1.56 & 0.23 & 98 & 1.7 & 0.32 \\
\hline 14 & 98.5 & 1.7 & 0.36 & 95 & 1.9 & 0.45 \\
\hline 15 & 99.5 & 1.9 & 0.29 & 96.5 & 2.2 & 0.4 \\
\hline 16 & 98.5 & 2.1 & 0.3 & 96 & 2.4 & 0.45 \\
\hline 17 & 97.2 & 3.1 & 0.28 & 95 & 3.5 & 0.38 \\
\hline 18 & 98.6 & 2.5 & 0.31 & 96 & 2.9 & 0.51 \\
\hline 19 & 97.5 & 1.5 & 0.24 & 95.7 & 1.8 & 0.44 \\
\hline 20 & 97 & 1.3 & 0.22 & 95.1 & 1.9 & 0.42 \\
\hline Avg & 98.70 & 1.91 & 0.28 & 96.44 & 2.37 & 0.41 \\
\hline SD & 0.905 & 0.437 & 0.045 & 1.174 & 0.528 & 0.060 \\
\hline
\end{tabular}

Table 2: Patient specific QA results for 20 IMRT cases.

ghosting was measured to be $0.2 \%$ for a-Si 1200 as compared to $0.8 \%$ for a-Si 1000 portal imager.

\section{Backscatter impact}

The in plane profiles for maximum field size $27 \times 27$ is shown in Figure 7. There is a significant improvement in a-Si 1200 portal imager when compared with a-Si1000 portal imager due to backscatter shielding material attached to the back of the panel of a-Si 1200 portal imager. As the field size reduces, so is the backscatter contribution as seen in Figure 7. This is visible in in plane direction in the upper half of imager panel where the arm is mounted on the metal bar which provides the largest source of backscatter.

\section{IMRT delivery}

The results of gamma evaluation for 20 dynamic IMRT cases were tabulated as shown in Table 2. There was an improvement in the area gamma values, average gamma and maximum gamma for a-Si 1200 over a-Si 1000 portal imager. The area gamma for a-Si 1200 portal imager was $98.70 \%$ as compared with $96.44 \%$ for a-Si 1000 portal imager.

\section{Discussion}

Before using any dosimetric tool for clinical purpose there is a need to study the dosimetric characteristic of that tool. Due to their excellent dosimetric characteristics and easiness to use the portal dosimetry and 2-D array have been widely adopted as patient specific QA tool. The dosimetric properties of a-Si 1200 proved its worth over a-Si 1000, film and other dosimetric system. Better understanding of the dosimetric characteristics is required for the efficient use and development of effective measurement tools for better accuracy. 
Citation: Mhatre V, Pilakkal S, Chadha P, Talpatra K (2018) Dosimetric Comparison of a-Si 1200 and a-Si 1000 Electronic Portal Imager for Intensity Modulated Radiation Therapy (IMRT). J Nucl Med Radiat Ther 9: 354. doi: 10.4172/2155-9619.1000354

Page 5 of 6

In this study, the linearity of EPID response was within $0.5 \%$ for low MU (2-10) as compared to $1.4 \%$ for a-Si 1000 portal imager and less than $1 \%$ for both the imager above $10 \mathrm{MU}$. This shows an improvement over previous reports for a-Si 1000 portal imager and other vendor EPID systems [31-33]. The dose rate and field size dependence of a-Si 1200 imager correlated well with ionization chamber measurement as compared with a-Si 1000 portal imager. Due to the backscatter arm shielding impact the output factor reduced for a-Si 1200 for larger field size and a variation of $1.3 \%$ for a-Si 1200 was observed as compared with $3.8 \%$ for a-Si 1000 . The total ghosting effect was found to be $<0.2 \%$ for a-Si 1200 when compared with a-Si 1000 . Our results are comparable to the results obtained by Reilly et al. [34-37]. This must be considered negligible for the application of pre-treatment dosimetric treatment verification.

The symmetry of the profiles for a-Si 1200 EPID was considerably improved over the a-Si 1000 imager, indicating the effectiveness of backscatter shielding in the new system. The impact of backscatter was previously studied on a-Si 1000 imager [38-41]. In this study, the gamma values obtained with a-Si 1200 portal dosimetry were found to be more consistent compared to those obtained with a-Si 1000 portal dosimetry due the improvement in dosimetric characteristics of a-Si 1200 portal imager.

\section{Conclusion}

The new aS1200 detector showed a significant dosimetric improvement when compared with previous aS1000 hence providing more accurate measurements. The ghosting effect has reduced and the impact of support arm backscatter is negligible with significant differences observed in comparison of IMRT gamma results and it allows the new EPID to be applied for pre-treatment QA.

\section{References}

1. Ju SG, Ahn YC, Huh SJ, Yeo IJ (2002) Film dosimetry for Intensity modulated radiation therapy: Dosimetric evaluation. Med Phys 29: 351-355.

2. Bucciolini M, Buonamici FB, Casati M (2004) Verification of IMRT fields by film dosimetry. Med Phys 31: 161-168.

3. Budgell GJ, Perrin BA, Mott JHL, Fairfoul J, Mackay RI (2004) Quantitative analysis of patient-specific dosimetric IMRT verification. Phys Med Biol 50: 103-119.

4. Childress NL, White RA, Bloch C, Salehpour M, Dong L, et al. (2005) Retrospective analysis of 2D patient-specific IMRT verifications. Med Phys 32 : 838-850.

5. Jursinic PA, Nelms BE (2003) A 2-D diode array and analysis software for verification of intensity modulated radiation therapy delivery. Med Phys 30 870-879.

6. Amerio S, Boriano A, Bourhaleb F (2004) Dosimetric characterization of a large area pixel-segmented ionization chamber. Med Phys 31: 414-420.

7. Spezi E, Angelini AL, Romani F, Ferri A (2005) Characterization of a 2D ion chamber array for the verification of radiotherapy treatments. Phys Med Biol 50: $3361-3373$.

8. Sta-Si M, Giordanengo S, Cirio R (2005) D-IMRT verification with a 2D pixel ionization chamber: dosimetric and clinical results in head and neck cancer. Phys Med Biol 50: 4681-4694.

9. Poppe B, Blechschmidt A, Djouguela A (2006) Two-dimensional ionization chamber arrays for IMRT plan verification. Med Phys 33: 1005-1015.

10. Herzen J, Todorovic M, Cremers F (2007) Dosimetric evaluation of a 2D pixel ionization chamber for implementation in clinical routine. Phys Med Biol 52: 1197-1208.

11. Sandra VC (2006) Fast, daily linac verification for segmented IMRT using electronic portal imaging. Radiother Oncol 80: 86-92.
12. Surendran S, Rao DP, Kunnanchath J, Cyriac SL (2014) Dynamic MLC-QA based portal dosimetry. IJERA 4: 134-137.

13. Nicolini G, Vanetti E, Clivio A, Fogliata A, Boka G, et al. (2008) Testing the portal imager GLAaS algorithm for machine quality assurance. Radiat Oncol 3: 1 .

14. Vaibhav MR, Parimal P (2017) Evaluation of ArcCHECK SNC Machine QA too for Modern Linear Accelerator. IJCTO 5

15. Sharma DS, Mhatre V, Heigrujam M, Talapatra K, Mallik S (2010) Portal dosimetry for pretreatment verification of IMRT plan: A comparison with 2D ion chamber array. J Appl Clin Med Phys 11: 238-248.

16. Surendra S, Rao DP, Cyriac SL, kunnanchat J, Majumdar SKD (2014) Study of feasibility of portal dosimetry in comparison with ImatriXX 2-D array system for IMRT and Rapid arc patient specific QA. IOSR-JEN 4: 11-15.

17. Abdelaziz D, Khalifa W, Sherbini NE (2015) Efficacy of use of A-Si EPID as imaging device in IMRT QA. IOSR-JAP 7: 27-43.

18. Jayesh K, Ganesh T, Suganthi D, Mohan R, Rakesh CJ, et al. (2013) Dosimetric comparison of aSi1000 EPID and ImatriXX 2-D array system for volumetric modulated arc and intensity modulated radiotherapy patient specific quality assurance. JPMS 1: 7

19. Mccurdy BMC, Greer PB (2009) Dosimetric properties of amorphous silicon EPID used in continuous acquisition mode for application to dynamic and arc IMRT. Med Phys 36.

20. Greer PB, Popescu CC (2004) Dosimetric properties of an amorphous silicon electronic portal imaging device for verification of dynamic intensity modulated radiation therapy. Med Phys 31: 285-295.

21. Wo'zniak B, Ganowicz M, Bekman A, Maniakowski Z (2005) Acomparison of the dosimetric properties of the Electronic Portal Imaging Devices (EPIDs) LC250 and aS500. Rep Pract Oncol Radiother 10: 249-254.

22. McDermott LN, Wendling M, Van Asselen B (2006) Clinical experience with EPID dosimetry for prostate IMRTpre-treatment dose verification. Med Phys 33: $3921-3930$.

23. Greer PB (2007) Off-axis dose-response characteristics of an amorphous silicon electronic portal imaging device. Med Phys 34: 3815-3824.

24. Pasma KL, Maarten LP, Kroonwijk MD (1999) Dosimetric verification of intensity modulated beams produced with dynamic multileaf collimator using an electronic portal imaging device. Med Phys 26: 2373-2378.

25. Grządziel A, Smolińska B, Rutkowski R, Ślosarek K (2007) EPID dosimetry configuration and pre-treatment IMRT verification. Rep Pract Oncol Radiother 12: $307-312$.

26. (2016) Truebeam technical reference guide: Volume 2 -Imaging P-1005924 002-B, Varian Medical System.

27. Miri N, Keller P, Zwan BJ, Greer P (2016) EPID-based dosimetry to verify IMRT planar dose distribution for the aS1200 EPID and FFF beams. J Appl Clin Med Phys 17: 292-304.

28. Greer PB, Popescu CC (2003) Dosimetric properties of an amorphous silicon electronic portal imaging device for verification of dynamic intensity modulated radiation therapy. Med Phys 30: 1618-1627.

29. McDermott LN, Louwe RJW, Sonke JJ, Van Herk M, Mijnheer BJ (2004) Dose-response and ghosting effects of an amorphous silicon electronic portal imaging device. Med Phys 31: 285-295

30. Van Esch A, Depuydt T, Huyskens DP (2004) The use of an a-Si-based EPID for routine absolute dosimetric pre-treatment verification of dynamic IMRT fields. Radiother Oncol 71: 223-234.

31. McDermott LN, Nijsten SM, Sonke JJ, Partridge M, Van Herk M, et al. (2006) Comparison of ghosting effects for three commercial a-Si EPIDs. Med Phys 33: $2448-2451$.

32. McCurdy BM, Greer PB (2009) Dosimetric properties of an amorphous-silicon EPID used in continuous acquisition mode for application to dynamic and arc IMRT. Med Phys 36: 3028-3039.

33. Podesta M, Nijsten SM, Snaith J (2012) Measured vs simulated portal images for low MU fields on three accelerator types: possible consequences for 2D portal dosimetry. Med Phys 39: 7470-7479.

34. Miri N, Baltes C, Keller P, Greer P (2015) Development of dose-to-wate 
Citation: Mhatre V, Pilakkal S, Chadha P, Talpatra K (2018) Dosimetric Comparison of a-Si 1200 and a-Si 1000 Electronic Portal Imager for Intensity Modulated Radiation Therapy (IMRT). J Nucl Med Radiat Ther 9: 354. doi: 10.4172/2155-9619.1000354

Page 6 of 6

conversion models for pre-treatment verification with the new aS1200 imager. Med Phys 42: 3393-3394.

35. Nicolini G, Clivio A, Vanetti E (2013) Evaluation of an a-Si-EPID with flattening filter free beams: Applicability to the GLAaS algorithm for portal dosimetry and first experience for pretreatment QA of RapidArc. Med Phys 40: 111719.

36. Nicolini G, Clivio A, Vanetti E, Tomatis S, Reggiori G, et al. (2015) Dosimetric testing of the new aS1200 MV imager with FF and FFF beams [poster] Radiother Oncol 115: S439.

37. Reilly AJ, Esch AV, Carver A (2015) Evaluation of a new Electronic Portal Imaging device for pre-treatment and in-vivo dosimetry (poster), $3^{\text {rd }}$ ESTRO forum.
38. Berry SL, Polvorosa CS, Wuu CS (2010) A field size specific backscatter correction algorithm for accurate EPID dosimetry. Med Phys 37: 2425-2434

39. Rowshanfarzad P, McCurdy BM, Sabet M, Lee C, O'Connor DJ, et al. (2010) Measurement and modeling of the effect of support arm backscatter on dosimetry with a Varian EPID. Med Phys 37: 2269-2278.

40. King BW, Greer PB (2013) A method for removing arm backscatter from EPID images. Med Phys 40: 071703

41. Ko L, Kim JO, Siebers JV (2004) Investigation of the optimal backscatter for an a-Si electronic portal imaging device. Phys Med Biol 49: 1723-1738. 